\title{
Optimization of PI Controller Gains in Nonlinear Controller of STATCOM Using PSO and GA
}

\author{
N. Farokhnia, R. Khoraminia and G.B. Gharehpetian \\ Department of Electrical Engineering \\ Amirkabir University of Technology (Tehran Polytechnic) \\ Tehran, Iran \\ Farokhnia@aut.ac.ir, rkh.1361@gmail.com, grptian@aut.ac.ir
}

\begin{abstract}
According to nonlinear operation of STATCOM, nonlinear controller has a better performance in comparison with linear controller. Regulating the DC capacitor voltage in STATCOM is a common task and can improve the system dynamic. The nonlinear control is based on exact linearization via feedback. A PI controller exists in this control system to regulate the capacitor voltage. In conventional scheme, the trial and error method has been used to determine PI controller coefficients. In this paper, the effect of PI gains on responses of $V_{d c}, I_{d}$ and Modulation Index (M) is presented. The exact calculation of optimized PI coefficients can be carried out to reduce disturbances and steady state error in DC link voltage. Therefore, in this paper, Particle Swarm Optimization (PSO) approach is used. It is shown that capacitor voltage tracks the reference value and vibrations are less than conventional status. Also, Genetic Algorithm (GA) has been used and compared with the results.
\end{abstract}

Index Terms - STATCOM, Nonlinear Controller, Optimized PI Coefficients, Particle Swarm Optimization and Genetic Algorithm

\section{INTRODUCTION}

STATic COMpensator (STATCOM) is a shunt Flexible AC Transmission System (FACTS) devices that can regulate line voltage at the Point of Common Coupling (PCC), balance loads or compensate load reactive power by producing the desired amplitude and phase of inverter output voltage. AC system is connected to a DC capacitor (energy storage device) through the inverter [1]. There are many possible configurations of Voltage Source Inverters (VSI) and consequently many different configurations of STATCOMs [2-3]. Many different control strategies such as Proportional-Integral (PI) controller, sliding mode controller [4] and nonlinear controller have been suggested to control STATCOM. Because of nonlinear operation of STATCOM, nonlinear controller is preferred over linear controller [5].
Moreover, in linear controller, four chosen sets of PI parameters may not be suitable for all ranges of operating points and finding these values are very time consuming and complex [6-7]. In nonlinear controller, the Generalized Averaged Method [8] has been used to determine the nonlinear time invariant continuous model of the system [9-11]. This model has been used to present a nonlinear control law based on exact linearization via feedback for STATCOM [12]. This method is particularly interesting because it transforms a nonlinear system into a linear one in terms of its input-output relationship. In [9-10], only q axis current has been regulated, but it should be noted that unlike other shunt compensators, large energy storage device that have almost constant DC voltage, makes STATCOM more robust and it also enhances the response speed. Therefore, there are two control objectives implemented in STATCOM. First one is qaxes current and the second objective is capacitor voltage in DC link [13]. The q-axes current tracks its corresponding reference value perfectly, but the capacitor voltage $\left(V_{d c}\right)$ is not fixed on reference ideally because of presence of a PI controller between the reference of the d-axes current $\left(I_{d}^{*}\right)$ and $\mathrm{V}_{\mathrm{dc}}$ error $\left(V_{d c}^{*}-V_{d c}\right)$. In other words, the performance indices (settling time, rise time and over shoot) have notable values. Thus, the optimized and exact determination of PI controller gains can lead to the reduction in system disturbances.

In this Paper, two well-known optimization methods (e.g., GA [14-15] and PSO [19-20]) are applied to find optimized values of PI gains and compare with each other. Two objective functions are defined. The determined PI coefficients are implemented in the controller to demonstrate the improvement of the convergence speed, reduction of error, the overshoot in the capacitor voltage and other circuit parameters. The results are compared with trial and error method, too. 


\section{CONFIGURATION OF STATCOM}

In this paper, a simplified STATCOM configuration, shown in Fig. (1), is considered. It consists of a voltage source inverter, a capacitor, $\mathrm{C}$, an inductance, $\mathrm{L}$ (representing the leakage inductance of the transformer and line) and a resistor, $R_{S}$ (representing the inverter and transformer conduction losses) on the AC side.

$V_{a}, V_{b}, V_{c}$ are called line voltages. $E_{a}, E_{b}, E_{c}$ are the inverter output voltage and $V_{d c}$ is the DC voltage.

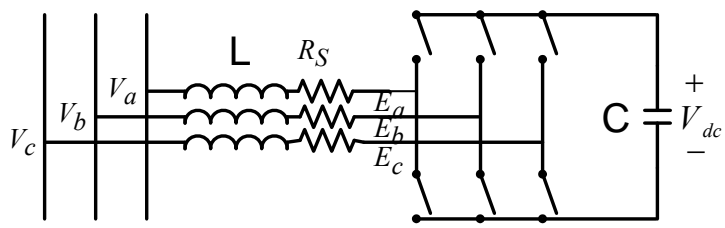

Figure 1. Representation of STATCOM

The angular velocity of the $\mathrm{AC}$ voltage and current vectors is $\omega$. Let us consider a system of reference $(d, q)$ rotating at the same speed, and let us note $\alpha$ to be the angle between $d$ axis and line voltage $\operatorname{vector}(\bar{E})$. The system equations are as follows [9]:

$$
\left[\begin{array}{c}
\frac{\mathrm{dI}_{\mathrm{d}}}{\mathrm{dt}} \\
\frac{\mathrm{dI}_{\mathrm{q}}}{\mathrm{dt}}
\end{array}\right]=\left[\begin{array}{cc}
-\frac{\mathrm{R}_{\mathrm{S}}}{\mathrm{L}_{\mathrm{S}}} & -\omega \\
\omega & -\frac{\mathrm{R}_{\mathrm{S}}}{\mathrm{L}_{\mathrm{S}}}
\end{array}\right]\left[\begin{array}{l}
\mathrm{I}_{\mathrm{d}} \\
\mathrm{I}_{\mathrm{q}}
\end{array}\right]+\frac{1}{\mathrm{~L}_{\mathrm{S}}}\left(\mathrm{V}_{\mathrm{dq}}-\mathrm{E}_{\mathrm{dq}}\right)
$$

The powers are expressed by equation (2):

$$
P=\frac{3}{2}\left(E_{d} I_{d}+E_{q} I_{q}\right), \quad Q=\frac{3}{2}\left(E_{d} I_{q}-E_{q} I_{d}\right)
$$

If $\alpha$ is chosen by zero, the $E_{q}$ voltage will be equal to zero and the reactive power becomes proportional to $E_{d} I_{q}$. To control the reactive power $(\mathrm{Q})$, it is sufficient to control $I_{q}$.

$$
\begin{aligned}
& E_{q}=0, \quad Q=\frac{3}{2} E_{d} I_{q} \\
& P=V_{d c} c \frac{d V_{d c}}{d t}
\end{aligned}
$$

Rewriting the Eq. (2) for capacitor voltage and substituting Eq. (4) in it, results in the third equation will be added to other two equations of Eq. (1)

By applying the Averaged Model used for control, only fundamental component of inverter output voltage is considered. The influence of all other harmonics is ignored.

The control variable is the firings angle $(\delta)$ with reference to the network voltage zero $\operatorname{crossing}\left(E_{j}\right)$. This model is used to simulate the system, but not to choose and tune the controller. A Generalized Averaging method [8] is used to get a continuous time invariant model of the converter. So, the averaged equations are as follows:

$$
\frac{d}{d t}\left[\begin{array}{c}
I_{d} \\
I_{q} \\
V_{d c}
\end{array}\right]=\left[\begin{array}{ccc}
-\frac{R_{S}}{L_{S}} & \omega & -\frac{M \cos \delta}{L_{S}} \\
-\omega & -\frac{R_{S}}{L_{S}} & -\frac{M \sin \delta}{L_{S}} \\
\frac{M \cos \delta}{C} & \frac{M \sin \delta}{C} & 0
\end{array}\right]\left[\begin{array}{c}
I_{d} \\
I_{q} \\
V_{d c}
\end{array}\right]
$$

\section{NONLINEAR CONTROL SCHEME FOR STATCOM}

The nonlinear control law is based on the theory of exact linearization via feedback [12]. In this law, the system has to be described by Eqs. (6-7). It is relative degree $r$ if Eqs. (9-10) are verified for all $x$ and all $k<r-1 . L_{f} h(x)$ is called $\mathrm{h}(\mathrm{x})$ derivative along $f$; it is defined by equation (8).

$$
\begin{aligned}
& \dot{\mathrm{x}}=\mathrm{f}(\mathrm{x})+\sum_{\mathrm{i}=1}^{\mathrm{m}} \mathrm{g}_{\mathrm{i}}(\mathrm{x}) \mathrm{u}_{\mathrm{i}} \\
& \mathrm{y}_{\mathrm{i}}=\mathrm{h}_{\mathrm{i}}(\mathrm{x}) \\
& \mathrm{L}_{\mathrm{f}} \mathrm{h}(\mathrm{x})=\frac{\partial \mathrm{h}(\mathrm{x})}{\partial \mathrm{x}} \mathrm{f}(\mathrm{x}) \\
& {\left[\mathrm{L}_{\mathrm{g} 1} \mathrm{~L}_{\mathrm{f}}^{\mathrm{k}} \mathrm{h}_{\mathrm{i}}(\mathrm{x}) \quad \mathrm{L}_{\mathrm{g} 2} \mathrm{~L}_{\mathrm{f}}^{\mathrm{k}} \mathrm{h}_{\mathrm{i}}(\mathrm{x}) \quad \cdots \quad \mathrm{L}_{\mathrm{gm}} \mathrm{L}_{\mathrm{f}}^{\mathrm{k}} \mathrm{h}_{\mathrm{i}}(\mathrm{x})\right]=0} \\
& \mathrm{~L}_{\mathrm{gi}} \mathrm{L}_{\mathrm{f}}^{\mathrm{r}_{\mathrm{f}}-1} \mathrm{~h}_{\mathrm{i}}(\mathrm{x}) \neq 0 \quad \text { for at Least one } 1 \leq \mathrm{j} \leq \mathrm{m}
\end{aligned}
$$

For STATCOM system, because of compensating the reactive power and eliminating the undesired internal dynamic, $Q$ and $V_{d c}$ are chosen as output control variables. Consequently, the $M$ and $\delta$ are chosen as two control inputs variables. So, a MIMO system is obtained as follows:

$$
\begin{aligned}
& \dot{X}=f(x)+g_{1}(x) u_{1}+g_{2}(x) u_{2}= \\
& {\left[\begin{array}{ccc}
-\frac{R_{S}}{L_{S}} x_{1} & \omega x_{2} & \frac{V_{S}}{L_{S}} \\
-\omega x_{1} & -\frac{R_{S}}{L_{S}} x_{2} & 0 \\
0 & 0 & 0
\end{array}\right]+\left[\begin{array}{c}
-\frac{x_{3}}{L_{S}} \\
0 \\
-\frac{x_{1}}{C}
\end{array}\right] u_{1}+\left[\begin{array}{c}
0 \\
-\frac{x_{3}}{L_{S}} \\
-\frac{x_{2}}{C}
\end{array}\right] u_{2}} \\
& Y=\left[\begin{array}{l}
h_{1}(X) \\
h_{2}(X)
\end{array}\right]=\left[\begin{array}{l}
\mathrm{x}_{1} \\
\mathrm{x}_{2}
\end{array}\right]
\end{aligned}
$$

Where $X$ and $U$ are state and input control vectors, respectively.

$$
\begin{aligned}
& X=\left[\begin{array}{l}
x_{1} \\
x_{2} \\
x_{3}
\end{array}\right]=\left[\begin{array}{c}
I_{d} \\
I_{q} \\
V_{d c}
\end{array}\right] \text { is state vector } \\
& U=\left[\begin{array}{l}
u_{1} \\
u_{2}
\end{array}\right]=\left[\begin{array}{l}
M \cos \delta \\
M \sin \delta
\end{array}\right] \text { is input control vector }
\end{aligned}
$$

The system described by equations (11-12) has a relative degree of $r=\{1,1\}$, and a fairly standard form. Solving the problem of reproducing a reference output, results in the following control law: 
$\left.\mathrm{U}(\mathrm{t})=\left[\begin{array}{cc}-\frac{\mathrm{L}_{\mathrm{S}}}{\mathrm{x}_{3}} & 0 \\ 0 & -\frac{\mathrm{L}_{\mathrm{S}}}{\mathrm{x}_{3}}\end{array}\right] \mathrm{c}-\begin{array}{c}-\frac{\mathrm{R}_{\mathrm{S}}}{\mathrm{L}_{\mathrm{S}}} \mathrm{x}_{1}+\omega \mathrm{x}_{2}+\frac{\mathrm{V}_{\mathrm{S}}}{\mathrm{L}_{\mathrm{S}}} \\ -\omega \mathrm{x}_{1}-\frac{\mathrm{R}_{\mathrm{S}}}{\mathrm{L}_{\mathrm{S}}} \mathrm{x}_{2}\end{array}\right]$

$\left.+\left[\begin{array}{c}\mathrm{v}_{1} \\ \mathrm{v}_{2}\end{array}\right]\right)=\left[\begin{array}{c}-\frac{\mathrm{L}_{\mathrm{S}}}{\mathrm{x}_{3}}\left(\mathrm{v}_{1}+\frac{\mathrm{R}_{\mathrm{S}}}{\mathrm{L}_{\mathrm{S}}} \mathrm{x}_{1}+\omega \mathrm{x}_{2}-\frac{\mathrm{V}_{\mathrm{S}}}{\mathrm{L}_{\mathrm{S}}}\right) \\ -\frac{\mathrm{L}_{\mathrm{S}}}{\mathrm{x}_{3}}\left(\mathrm{v}_{2}+\omega \mathrm{x}_{1}+\frac{\mathrm{R}_{\mathrm{S}}}{\mathrm{L}_{\mathrm{S}}} \mathrm{x}_{2}\right)\end{array}\right]$

Where, $v_{1}$ and $v_{2}$ are the output reference and new inputs. $y_{1}, y_{2}$ are their corresponding outputs.

Two proportional controllers are chosen to construct the new inputs $\left(v_{1}\right.$ and $\left.v_{2}\right)$ and an external PI controller is chosen to regulate dc link voltage as shown in Fig. 2. Thus, the system with nonlinear control law and three controllers is modeled.

Considering the $I_{q}$ channel, the equivalent closeloop transfer function can be expressed by the following equation:

$$
\frac{\mathrm{I}_{\mathrm{q}}}{\mathrm{I}_{\mathrm{q}}{ }^{*}}=\frac{1}{1+\mathrm{S} / \lambda}
$$

Where $\lambda$ determines the response speed of the reactive current.

Substituting Eq.(13) in Eq.(11) and considering Eq.(14), results in the following equation:

$$
\left[\begin{array}{l}
\dot{x}_{1} \\
\dot{x_{2}}
\end{array}\right]=\left[\begin{array}{l}
v_{1} \\
v_{2}
\end{array}\right]=\left[\begin{array}{l}
\lambda_{1}\left(x_{1}^{*}-x_{1}\right) \\
\lambda_{2}\left(x_{2}^{*}-x_{2}\right)
\end{array}\right]
$$

Solving this differential equation, shows that $\mathrm{x}_{\mathrm{i}}$ tends to its reference value $\left(x_{i}^{*}\right)$.

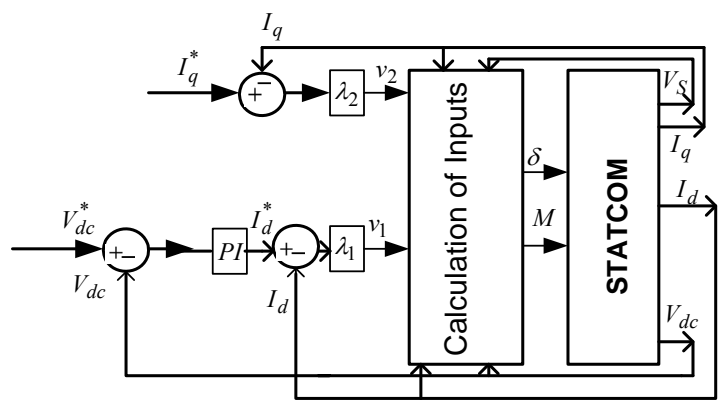

Figure 2. STATCOM controller

\section{Particle SWARM Optimization (PSO)}

Optimization methods often detect optima in difficult optimization problems faster than traditional methods [22]. One of the most powerful swarm intelligence-based optimization methods, named PSO, was introduced by Kennedy and Eberhart [19].

The general principles for the PSO algorithm are stated as follows. Suppose that the search space is $n$ dimensional, then the $i^{\text {th }}$ particle can be represented by a $n$-dimensional vector, $X_{i}=\left[x_{i 1}, x_{i 2}, \ldots, x_{i n}\right]^{T}$, and velocity $V_{i}=\left[v_{i 1}, v_{i 2}, \ldots, v_{i n}\right]^{T}, \quad$ where $i=1,2, \ldots, N$ and $N$ is the size of population.

In PSO, particle $i$ remembers the best position it visited so far, referred to as $P_{i}=\left[p_{i 1}, p_{i 2}, \ldots p_{i n}\right]^{T}$, and the best position of the best particle in the swarm is referred as $G=\left[g_{1}, g_{2}, \ldots, g_{n}\right]^{T}[21]$.

Each particle $i$ adjusts its position in next iteration $t+1$ with respect to Eqs. (16) and (17) [22]:

$$
\begin{gathered}
V_{i}(t+1)=\omega(t) V_{i}(t)+c_{1} r_{1}\left(P_{i}(t)-X_{i}(t+1)\right) \\
+c_{2} r_{2}\left(G_{i}(t)-X_{i}(t+1)\right) \\
X_{i}(t+1)=X_{i}(t)+\chi V_{i}(t+1)
\end{gathered}
$$

Where $\omega(t)$ is inertia coefficient which gradually decreases from 1 at first iteration to a small magnitude about zero on a straight line. $\chi$ is constriction factor which is used to limit velocity. $c_{1}$ and $c_{2}$ denote the cognitive and social parameters respectively. $r_{1}$ and $r_{2}$ random real numbers drawn from uniformly distributed interval $[0,1]$. The inertia coefficient in (16) is employed to manipulate the impact of the previous history of velocities on the current velocity. Therefore, $\omega(t)$ resolves the tradeoff between the global and local exploration ability of the swarm. A large inertia coefficient encourages global exploration while small one promotes local exploration. Experimental results suggest that it is preferable to initialize it to a large value, giving priority to global exploration of search space, and gradually decreasing as to obtain refined solution [21-22].

\section{A. Objective Function}

ITAE (Integral Time Absolute Error) criterion is widely adopted to evaluate the dynamic performance of the control system [16]. The index ITAE is expressed in equation (18), as follows:

$$
J_{I T A E}=\int_{0}^{T} t|e(t)|
$$

Where the upper limit $T$ is a finite time chosen so that the integral approaches a steady-state value and is usually chosen as the setting time $T_{\mathrm{s}}$.

For the STATCOM system, the adopted objective function is presented by the following equation:

$Q_{f}(Z)=\sum_{i} m_{i} f_{i}(Z)$

Where

$f_{i}(Z)=\sum_{j} \omega_{j} \int_{0}^{T} t\left|e_{j}(t)\right|$ 
$f_{i}$ is a performance index corresponding to the No. $i$ objective. $m_{i}$ is a weighted factor corresponding to the objective. $e_{j}(t)$ is the error between the real value of the No.j controlled variable and its desired value. $\omega_{i}$ is the weighted factor corresponding to the No.j controlled variable. Vector $Z=\left[Z_{1}, Z_{2}, \ldots, Z_{n}\right]$ is the control system parameters (i.e., PI parameters).

For the STATCOM, two objective functions are defined. The objective function deduced by Eq. (18) is expressed by the following equations:

$$
\begin{aligned}
& Q_{f}(Z)=1000\left(\int_{0}^{T} t\left|V_{d c}(t)-V_{d c R E F}\right|+t \mid I_{d}((t) \mid\right. \\
& Q_{f}(Z)=f(Z)=1000 \int_{0}^{T} t\left|V_{d c}(t)-V_{d c R E F}\right| \\
& \text { Where, } \quad Z=\left[\begin{array}{ll}
K_{P} & K_{I}
\end{array}\right]
\end{aligned}
$$

The Eq. (21) is used when the goal is controlling both the $V_{d c}$ and $I_{d}$ which is named double objective function. Eq. (20) should be used when $V_{d c}$ is individually regulated which is named single objective function.

\section{Simulation RESUlTS}

The case study parameters of the system, shown in Fig. 1, are as follows:

$C=490(\mu \mathrm{F}), F=50 \mathrm{~Hz}, R_{s}=.28(\Omega), L=0.0013(\mathrm{H})$, $V_{a}=110_{\mathrm{rms}(\mathrm{L}-\mathrm{L})}(\mathrm{V}), V_{d c}=200(\mathrm{~V})$, Initial voltage $=200^{\mathrm{V}}$

The reference $I_{q}$ has a step change from zero to $15 \mathrm{~A}$ at $t=0.02 \mathrm{~s}$. $\lambda_{1}$ and $\lambda_{2}$ are selected equal to 1000 .

In this section, the effect of PI gains on voltage regulation is shown by using unsuitable PI gains. Then PI gains, computed through trial and error method, are compared with ones computed by PSO with two objective functions and finally the results of PSO are compared with the results GA.

Randomly, 0 and 10 are selected for $K_{p}$ and $K_{I}$, respectively. Fig. 3 shows the $V_{d c}$ response.

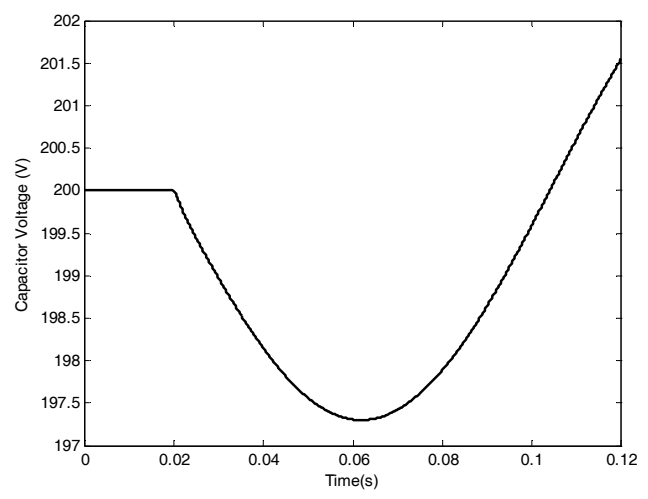

Figure 3. Capacitor voltage response to random PI gains

It is obvious that these values result in divergence and are improper for controlling the STATCOM. Consequently, PI coefficients cannot be determined randomly. The ordinary solution method for determination of PI gains is trial and error method. Many pairs should be tested. Then the best of them are selected. Some benchmarks such as steady state error and fluctuations are effective in choosing PI gains. Every one may select a unit pair and there is no good performance guaranty for them. Here, a set of forty pairs are studied and finally PI gains are selected to be $K_{p}=1$ and $K_{I}=70$. In PSO method, the number of population and iteration are 20 and 200, respectively. The objective functions are given by Eqs. 21 and 22 . The calculations are offline; therefore the running time (about 20 minutes) is not important. The three PI pairs from trial and error, single-objective (Eq. 22) PSO and double objective (Eq. 21) PSO methods have been applied to STATCOM. The corresponding time domain simulation plots for $V_{d c}, I_{d}, M, \delta$ and $I_{q}$ have been compared in figures (4)-(7). As shown in Fig. 4, the best regulation of $V_{d c}$ is obtained by PSO with single and double objective functions. The overshoot is very small and voltage is approximately fixed on $200 \mathrm{~V}$. But as it was predicted, the performance of single-objective function is better and double objective function response has a teeny steady state error. The presence of high frequency fluctuations in single-objective function response causes $I_{d}$ and $M$ to reach to their corresponding nominal values with high frequency fluctuations (see Figs. 5 and 6). Thus if the objective is to reduce oscillations in addition to voltage regulation, the double-objective function has a relative superiority over single-objective function and has to be chosen. The results of implementing doubleobjective function are shown with black color in Figs. (4-7). Double-objective function completely removes high frequency oscillations from $I_{d}$ and $M$ responses and converges with higher speed. All methods have a nearly same $\delta$ and $I_{q}$ responses (Fig. 7).

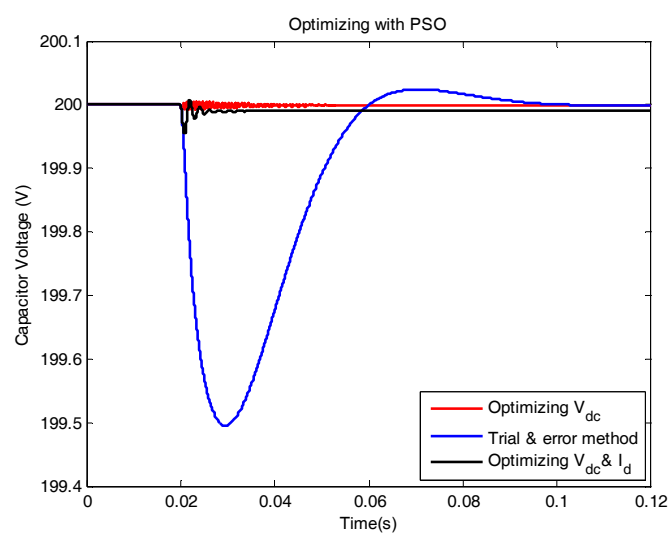

Figure 4. Capacitor voltage response 


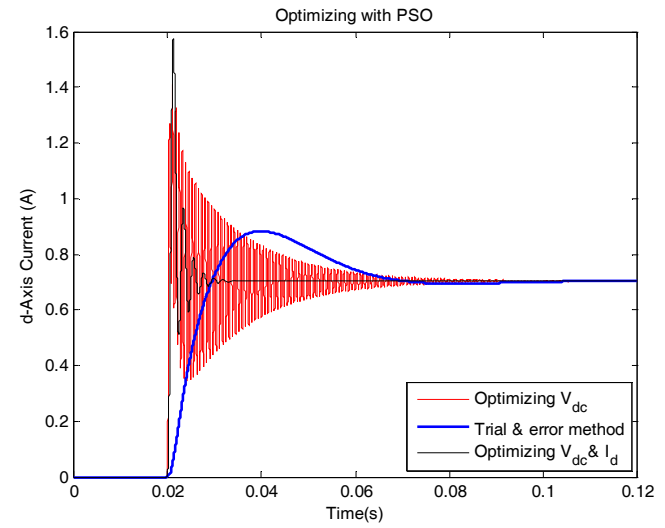

Figure 5. d-axis current response

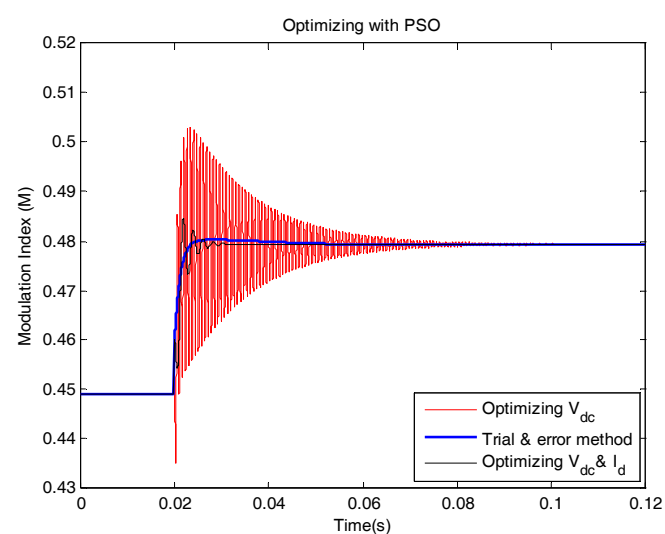

Figure 6. Modulation Index response
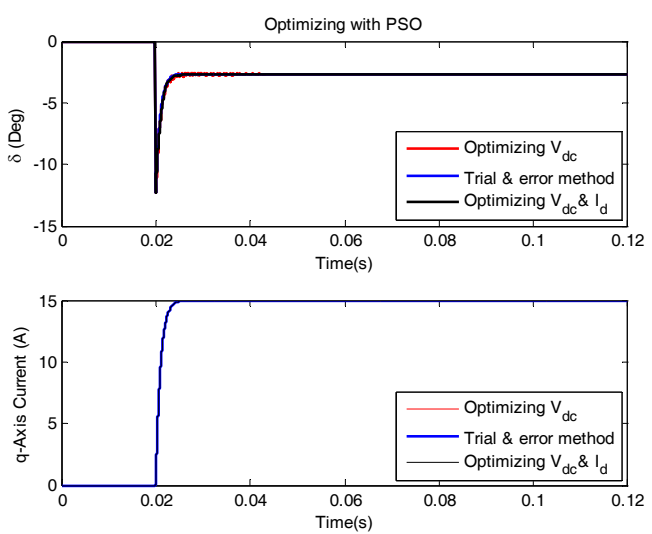

Figure 7. Phase difference and q-axis current

\section{COMPARISON BETWEEN PSO AND GA}

In this section, GA [18] is employed and compared with PSO. The results of running GA and PSO are used in table 1.

Comparison between two methods with a same function shows that PSO results in fitness function with lower value. Figures 8-10 compare PSO and GA for $V_{d c}, I_{d}$ and $M$ responses with two types of objective functions.

TABLE 1. RESULTS OF PSO AND GA

\begin{tabular}{|c|c|c|c|}
\hline Method & $\begin{array}{l}\text { Type of } \\
\text { Function }\end{array}$ & $\mathrm{K}_{\mathrm{P}} \& \mathrm{~K}_{\mathrm{I}}$ & $\begin{array}{l}\text { Fitness Function } \\
\text { value }\end{array}$ \\
\hline \multirow{2}{*}{ PSO } & $\begin{array}{c}\text { Single- } \\
\text { Objective }\end{array}$ & $\begin{array}{c}\mathrm{K}_{\mathrm{P}}=610.9952 \\
\mathrm{~K}_{\mathrm{I}}=700\end{array}$ & 0.0084 \\
\hline & $\begin{array}{l}\text { Double- } \\
\text { Objective }\end{array}$ & $\begin{array}{l}\mathrm{K}_{\mathrm{P}}=65 \\
\mathrm{~K}_{\mathrm{I}}=150\end{array}$ & 4.9996 \\
\hline \multirow{2}{*}{ GA } & $\begin{array}{c}\text { Single- } \\
\text { Objective }\end{array}$ & $\begin{aligned} \mathrm{K}_{\mathrm{P}} & =617.9668 \\
\mathrm{~K}_{\mathrm{I}} & =39.1076\end{aligned}$ & 0.0089 \\
\hline & $\begin{array}{l}\text { Double- } \\
\text { Objective }\end{array}$ & $\begin{array}{c}\mathrm{K}_{\mathrm{P}}=1.7748 \\
\mathrm{~K}_{\mathrm{I}}=150\end{array}$ & 5.1100 \\
\hline \multirow{2}{*}{$\begin{array}{l}\text { Trial \& } \\
\text { Error }\end{array}$} & $\begin{array}{c}\text { Single- } \\
\text { Objective }\end{array}$ & $\mathrm{K}_{\mathrm{P}}=1 \mathrm{~K}_{\mathrm{I}}=70$ & 0.4030 \\
\hline & $\begin{array}{c}\text { Double- } \\
\text { Objective }\end{array}$ & $\mathrm{K}_{\mathrm{P}}=1 \mathrm{~K}_{\mathrm{I}}=70$ & 5.4095 \\
\hline
\end{tabular}
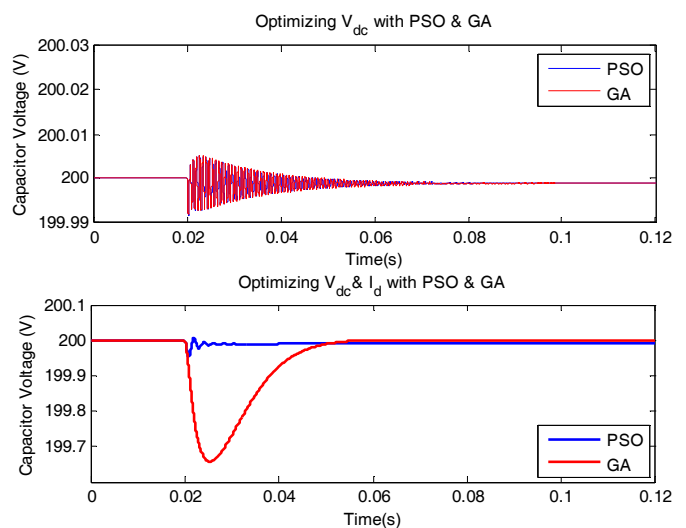

Figure 8. Capacitor voltage response
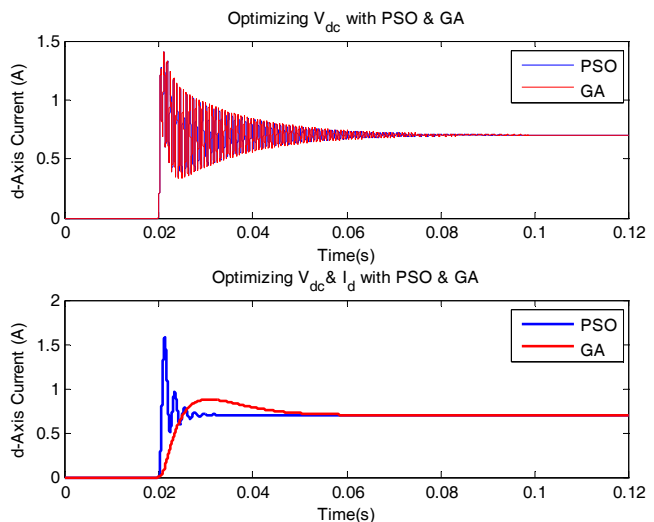

Figure 9. d-axis current response 

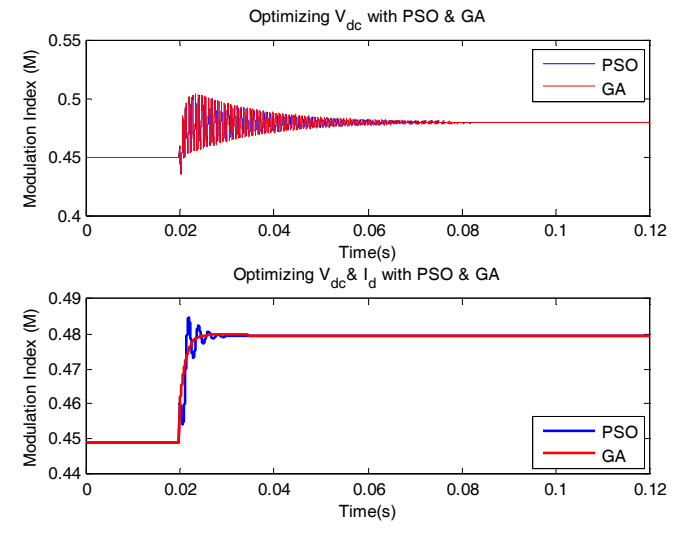

Figure 10. Modulation Index response

In Fig. 9, PSO response has more disturbances but faster convergence speed in the case of optimization of Vdc \& Id. Generally, PSO responses have less fluctuation in comparison with GA responses in the case of optimization of $\mathrm{Vdc}$. In the case of optimization of double-objective function for PSO, $\mathrm{Vdc}$ response reaches to steady state with higher speed and less fluctuation, Id response reaches to steady state with higher speed and more fluctuations and $\mathrm{M}$ response has not a good performance in comparison with GA responses.

\section{CONCLUSION}

The nonlinear control method of the STATCOM which is based on the exact linearization via feedback has a proportional-integral controller with unknown PI parameters which they have a remarkable influence on responses of system variables such as line current, $M$ and DC link voltage. Traditional solution is the calculation of these coefficients by using trial and error method. In this paper, PSO with two types of objective function has been used in determination of PI parameters and compared with GA. It is shown that the PSO method leads to a better regulation of DC link voltage, $\mathrm{d}$ and $\mathrm{q}$ axis currents and other circuit parameters. Also, the time of reaching to steady state value, settling time the fluctuations and overshoot have been decreased, too.

\section{REFERENCES}

[1] N. G. Hingorani and L. Gyugyi, Understanding FACTS, Concepts and Technology of Flexible AC Transmission Systems. New York: IEEE Press, 1999, 0-7803-3455-8.

[2] S. Iyer, A. Ghosh and A. Joshi, "Inverter topologies for DSTATCOM applications-a simulations study" Electr. Power Syst. Res. 75 (2005) (August (3)), pp. 161-170 (Elsevier)

[3] Lauttamus, P.; Tuusa, H.; "Comparison of Five-Level Voltage-Source Inverter Based STATCOMs" IEEE Power Conversion Conference, 2-5 April 2007 Page(s):659 - 666

[4] Hung-Chi Tsai; Chia-Chi Chu; "Nonlinear STATCOM Controller using Passivity-Based Sliding Mode Control" IEEE APCCAS, 4-7 Dec. 2006 Page(s):1996 - 1999
[5] Yazdani, A.; Crow, M.L.; Guo, J.; "A comparison of linear and nonlinear STATCOM control for power quality enhancement" IEEE Power and Energy Society General Meeting - Conversion and Delivery of Electrical Energy in the 21st Century, 20-24 July 2008 Page(s): 1 - 6

[6] Schauder, C. Mehta, H. "Vector analysis and control of advanced static VAr compensators" IEE Proceedings on Generation, Transmission and Distribution Volume 140, Issue 4, July 1993 Page(s):299 - 306

[7] Soto, D.; Pena, R.; "Nonlinear control strategies for cascaded multilevel STATCOMs" IEEE Transaction on Power Electronics, Vol. 19, Issue 4, Oct. 2004 Page(s):1919- 1927

[8] Sanders, S.R.; Noworolski, J.M.; Liu, X.Z.; Verghese, G.C.; "Generalized averaging method for power conversion circuits" IEEE Transaction on Power Electronics, Vol. 6, April 1991 Page(s):251-259

[9] P. Petitclair, S. Bacha, and J. P. Rognon, "Averaged modeling and nonlinear control of an ASVC (advanced static VAr compensator)," in Proc. IEEE/PESC'96 Annu.. Meeting, Jun. 1996, pp.753-758.

[10] Petitclair, P. Bacha, S. Ferrieux, J.-P. "Optimized linearization via feedback control law for a STATCOM" In IEEE Industry Applications Conference Volume 2, 5-9 Oct. 1997 Page(s):880 - 885

[11] Zhichang Yuan; Qiang Song; Wenhua Liu; Qingguang Yu "Nonlinear Controller for Cascade H-Bridge Inverter-Based STATCOM" In IEEE Transmission and Distribution Conference 2005 Page(s): 1 - 5

[12] J. E. Slotine and W. Li. Applied nonlinear control. Prentice Hall, New Jersey, 1991.

[13] N.C. Sahoo, B.K. Panigrahi, P.K. Dash and G. Panda "Application of a multivariable feedback linearization scheme for STATCOM control" Electric Power Syst. Res. 62 (2002) (No. 1), pp. 81-91

[14] Goldberg D.E., Genetic Algorithm in Search, Optimization and Machine Learning, MA: Addison Wesley, 1989.

[15] Davis L., Handbook of Genetic Algorithm, New York: Van Nostrand, 1991

[16] Xu Feng, Li Donghai, Xue Yali, "Comparing and optimum seeking of PID tuning methods based on ITAE index," Proceedings of the CSEE, vol. 23, no. 8, Aug., 2003.

[17] Senjyu, T.; Miyazato, Y.; Yona, A.; Urasaki, N.; Funabashi, T.; "Optimal Distribution Voltage Control and Coordination With Distributed Generation" IEEE Transactions on Power Delivery, Volume 23, April 2008 Page(s):1236 - 1242

[18] Farokhnia, N.; Fathi, S.H.; Khoraminia, R.; Hosseinian, S.H.; "Optimization of PI coefficients in DSTATCOM nonlinear controller for regulating DC voltage using Genetic Algorithm" 4th IEEE Conference on Industrial Electronics and Applications, ICIEA 2009. 25-27 May 2009 Page(s): $2291-2296$.

[19] Kennedy J, Eberhart R.C. "Particle Swarm Optimization" IEEE International Conference on Neural Networks, Perth, Australia, 1995, vol. IV, pp. 1942-1948.

[20] Tripathi P.K, Bandyopadhyay S, Pal S.K. Multi-Objective Particle Swarm Optimization with time variant inertia and acceleration coefficients. Information Sciences 177 (2007) 5033-5049.

[21] Kaviani, A. Kashefi; Fathi, S.H.; Farokhnia, N.; Ardakani, A. Jahanbani; "PSO, an effective tool for harmonics elimination and optimization in multi-level inverters" 4th IEEE Conference on Industrial Electronics and Applications, 2009. ICIEA 2009. 25-27 May 2009, Page(s):2902 - 2907.

[22] Konstantinos E. Parasopoulos and Michael N. Vrahatis "On the Computation off All Global Minimizers through Particle Swarm optimization" IEEE Trans. On Evolutionary Computation, vol. 8, No. 3, June 2004. 